\title{
Outcomes of older people receiving intensive care in Victoria
}

\section{Graeme J Duke MD, FCICM, FANZCA Intensive Care Physician \\ Anna Barker MPthy(Geriatrics), PhD Senior Research Fellow 2 \\ Cameron I Knott FRACP, FCICM Intensive Care Physician \\ John D Santamaria MD, FRACP, FCICM Clinical Director of Intensive Care \\ 1Box Hill Hospital, Melbourne, VIC \\ 2 Centre of Research Execllence in Patient Safety, Monash University, Melbourne, VIC. 3 Austin Health Melbourne, VIC \\ 4 St Vincents Hospital Melbourne \\ Melbourne, VIC. \\ graeme.duke@ easternhealth.org.au}

MJA 2014; 200: 323-326 doi: 10.5694/mjal3.10132

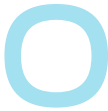

lder people (those aged 65 years or more) comprise $14 \%$ of the Australian population and are expected to represent $26 \%$ of the population by 2051., ${ }^{1,2}$ Several recent reports warn of a rapid growth in demand for intensive care services by older patients, particularly the very old (80 years or older), arising from the combined effect of ageing demographics, expansion of intensive care services, advances in therapeutics and technology, and the evolution of community expectations. ${ }^{2-6}$

Providing intensive care services for any age group involves outcome, resource and ethical considerations. ${ }^{2-8}$ Intensive care may not benefit those with irreversible disease or extreme frailty. Thus, clinicians, patients, families and the community face complex management and end-of-life decisions about the appropriate use of life-support therapies. 9

Age alone is an unreliable predictor of outcome $\mathrm{e}^{8-10}$ and maybe a physiological self-selector. ${ }^{11}$ Providing invasive or complex interventions to the very old may still be justified in the setting of reversible disease. ${ }^{8-11}$ Mechanical ventilation therapy is the most common life-support therapy and accounts for $70 \%$ of the clinical workload in an intensive care unit (ICU), but also confers a threefold increase in mortality risk. ${ }^{12}$

Resource supply (ICU bed stock) is a substantial rate-limiting factor to the delivery of intensive care services. ${ }^{13}$ Judicious administration of finite and costly intensive care services is challenging in the context of increasing demand. Therefore, it is reasonable for the community and governments to seek reassurances about access to, and the quality of, intensive care services for older people.

Delivering quality intensive care services includes timely identification and assessment of the patient whose

Objective: To assess trends in service use and outcome of critically ill older people (aged $\geqslant 65$ years) admitted to an intensive care unit (ICU).

Design, patients and setting: Retrospective cohort analysis of administrative data on older patients discharged from ICUs at all 23 adult public hospitals with onsite ICUs in Victoria between 1 July 1999 and 30 June 2011. Subgroups examined included those aged $\geqslant 80$ years, major diagnosis categories, and those receiving mechanical ventilation.

Main outcome measures: Resource use and hospital survival; also length of stay (LOS) and discharge destination trends.

Results: Over 12 years, 108171 people aged $\geqslant 65$ years were admitted to ICUs; of these, 49912 (46.1\%) received mechanical ventilation and 17772 (16.4\%) died. Despite an increase in the older age population (2.5\% per annum) and acute care admissions (7.3\% per annum) over the period studied, there was a net reversal in prevalence trends for ICU admissions ( $-1.7 \%$ per annum; $P=0.04$ ) and admissions of patients requiring mechanical ventilation $(-1.6 \%$ per annum) in the 8 years since 2004. Annual risk-adjusted mortality fell (odds ratio, 0.97 per year; $95 \% \mathrm{Cl}, 0.96-0.97$ per year; $P<0.001$ ) without prolongation of hospital or ICU LOS ( $P=0.49$ ) or discharge to residential aged care (RAC). Similar trends were noted in all a priori subgroups.

Conclusions: Improved hospital survival without an increase in demand for ICU admission or RAC or an increase in LOS suggests there has been improvement in the care of the older age population.

condition is deteriorating, access to relevant diagnostic and consultation services, and appropriate therapeutic and rehabilitation interventions, integrated with end-of-life care and palliation services when curative therapy is no longer beneficial. Without robust measures of morbidity and mortality, it is unclear if this is being achieved.

Our primary goal in this investigation was to identify temporal trends in resource use and outcome of critically ill patients aged 65 or more years admitted to an ICU in the public health care system in Victoria.

\section{Methods}

We undertook a retrospective cohort study of public hospital ICU admissions of people aged 65 years or older in Victoria between 1 July 1999 and 30 June 2011. The Victorian Department of Health provided the dataset and approved analysis and publication.

Population data from the Australian Bureau of Statistics were used to gen- erate relevant age-matched prevalence rates. ${ }^{1}$ Hospital data were extracted from the Victorian Admitted Episodes Dataset (VAED), an administrative database of all public hospital admissions in Victoria. ${ }^{14}$ Public hospitals with an accredited adult ICU were eligible for inclusion. ${ }^{15}$ "Older age" was defined as being aged 65 years or older at the time of hospital admission, and "very old" as 80 years or older. $^{2}$

We performed secondary analysis on the following subgroups: the very old $\left(\geqslant 80\right.$ years $\left.{ }^{2-5}\right)$; those receiving mechanical ventilation in the ICU; ${ }^{12}$ and common diagnosis groups according to the classification system of the International statistical classification of diseases and related health problems, 10th revision, Australian modification (ICD-10-AM). ${ }^{16}$ We have included results for younger patients (under 65 years) admitted to an ICU, and for older people not admitted to an ICU, where relevant, for comparison. 


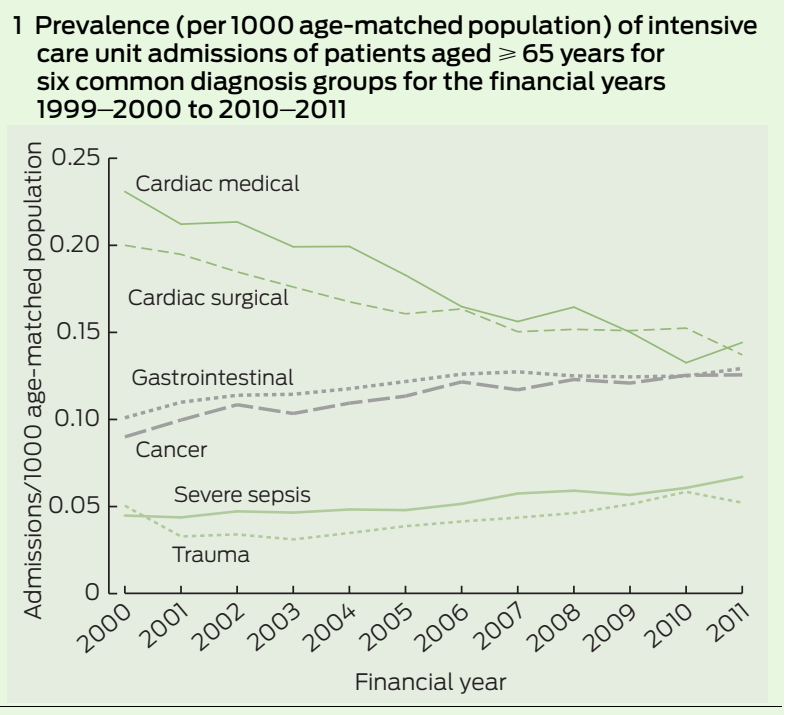

All trends $P<0.01$

2 Annual risk-adjusted age-matched mortality rate for older intensive care unit patients (aged $\geqslant 65$ years) for the financial years 1999-2000 to 2010-2011

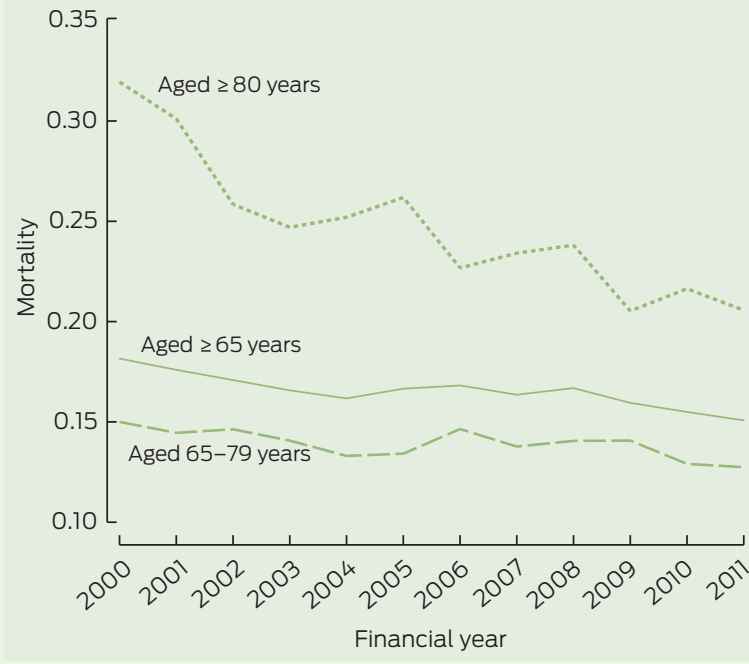

All trends $P<0.01$
Demographic characteristics and casemix data were extracted from the VAED. ${ }^{14}$ Chronic disease burden was estimated using the Charlson Comorbidity Index ${ }^{17}$ and Elixhauser model comorbidity measures. ${ }^{18}$ The predicted mortality risk $\left(\operatorname{Pr}_{\text {death }}\right)$ was calculated using the critical care outcome prediction equation (COPE) model ${ }^{19}$ as a surrogate marker of acuity level of the condition of ICU patients.

\section{Outcome measures}

The primary outcome was riskadjusted hospital mortality. Riskadjustment was performed using the
COPE model for all ICU admissions, and the hospital outcome prediction equation. ${ }^{20,21}$ These validated models predict hospital mortality from preadmission demographic variables and diagnosis on admission.

Secondary outcomes and surrogate measures of morbidity included length of stay (LOS) in ICU and hospital, and hospital discharge destination (home, rehabilitation facility, or residential aged care $[\mathrm{RAC}])$. These data were extracted from the VAED.

The number of ICU beds per year, as a crude measure of resources, was estimated from the ratio of (total) ICU treatment days to the number of calendar days. ICU occupancy was calculated using either the age-matched state population (for prevalence rates), or the relevant hospital or ICU subpopulation (for resource use and proportional rates).

\section{Statistical analysis}

We analysed data with Stata/MP statistical software, version 11.2 (StataCorp). Data were grouped according to financial year and presented as mean and standard deviation (SD), or median and interquartile range (IQR) for skewed data.

Temporal trends in binary variables (eg, death) were assessed by logistic regression, including the year of observation with the COPE-predicted mortality (as a casemix and severity adjustor) and the presence of comorbid conditions as the explanatory variables. Trends in continuous variables (eg, bed numbers and LOS) were assessed by negative binomial regression ${ }^{22}$ using the same explanatory variables plus hospital LOS as the exposure variable. A $P$ value $<0.05$ was considered significant.

Over the 12-year observation period, there were 8.39 million adult admissions $(61 \%$ of the state total) to these hospitals, including 214826 adult patients $(2.6 \%)$ admitted to ICUs, of whom 188105 (87.6\%) survived. The prevalence of acute hospital (with or without ICU) admission for those aged $\geqslant 65$ years increased from 317.2 to 448.6 per 1000 population $(P<0.001)$, an average increase of $7.3 \%$ per annum.

The number (proportion) of patients aged $\geqslant 65$ years admitted to hospital, to ICU, and requiring mechanical ventilation in the ICU was 3.50 million (40.7\%), 108171 (50.4\%), and $49912(46.1 \%)$, respectively. For those aged $\geqslant 80$ years, these were $1014969(11.8 \%), 28198$ (13.1\%), and 10705 (5.0\%), respectively. Annual population and admission data are available in Appendix 1 (online at www.mja.com.au).

\section{Casemix}

There were 74181 patients (68.6\%) aged $\geqslant 65$ years admitted to an ICU after an emergency presentation, 89967 (83.2\%) from home, 13801 $(12.8 \%)$ from another health service, and $486(0.4 \%)$ from an RAC facility. Almost three-quarters of patients aged $\geqslant 65$ years admitted to an ICU (79629 [73.7\%]) had at least one clinically significant comorbid condition.

There were several important temporal trends in casemix, including increases in admissions after an emergency presentation (from $66.3 \%$ to $71.9 \% ; P<0.001)$ and in interhospital transfers (from $10.8 \%$ to $14.4 \%$; $P<0.001)$. There was a substantial decline in cardiac medical and cardiac surgical admissions $(P<0.001)$, and a steady rise in admissions following gastrointestinal surgery, cancer and severe sepsis $(P<0.01$; Box 1$)$.

Further data are available in Appendix 1 and Appendix 2 (online at www.mja.com.au)

\section{Population data}

By 2011, the Victorian population was 5.66 million, with $13.8 \%$ aged $\geqslant 65$ years and $3.9 \%$ aged $\geqslant 80$ years. The population aged $\geqslant 65$ years increased by an average of $2.5 \%$ per annum $(P<0.001)$.

Adult intensive care services were available in $23(16 \%)$ of 141 public hospitals; none excluded patients from admission based on their age.

\section{Outcome}

Overall mortality rates among patients aged $\geqslant 65$ years and $\geqslant 80$ years who were admitted to hospital were $2.4 \%$ and $4.6 \%$, respectively. Most of these patients (78.8\%) were not admitted to an ICU.

There were 17772 deaths among ICU patients aged $\geqslant 65$ years, giving a 
mortality rate of $16.4 \%$. Mortality rates were higher among those aged $\geqslant 80$ years $(24.1 \%)$ and those receiving mechanical ventilation in the ICU (24.6\%). Comparative mortality rates for younger adults (aged $<65$ years) admitted to hospital, admitted to an ICU, and receiving mechanical ventilation in the ICU were $1.2 \%, 8.4 \%$, and $18.7 \%$, respectively. ${ }^{12}$

Trend analysis showed a significant decline in (both crude and riskadjusted) hospital mortality rates for ICU patients across all age groups, including the $\geqslant 65$ years group (odds ratio for death, 0.97 per year; $95 \% \mathrm{CI}$, 0.96-0.97 per year; Box 2). Similar survival trends were observed in the mechanical ventilation subgroup and in the diagnostic groups (Appendix 2; online at www.mja.com.au).

These favourable survival trends did not appear to be the consequence of a rise in the number of low-acuity admissions, as measured by comorbidity rates and predicted risk of death $(P=0.12$; Appendix 3; online at www.mja.com.au). Nor was there an increase in mortality rate among those not admitted to an ICU (and excluded from the study population); the risk-adjusted mortality rate for this group fell from $2.4 \%$ to $1.5 \%$ per annum $(P<0.001)$.

Of the 90399 older people admitted to an ICU who survived to hospital discharge, most were either discharged home $(58.9 \%)$ or transferred to a subacute facility for rehabilitation (30.2\%); 1573 (1.7\%) were discharged to an RAC facility for the first time. We identified no significant temporal trends in discharge destination.

\section{Resource use}

Over 12 years, the growth in ICU resources (total beds) exceeded population growth by $4.7 \%$ per annum (an increase from 4.03 to 4.55 ICU beds per 100000 population), ${ }^{16}$ but the prevalence of ICU admission for older people revealed an unexpected biphasic pattern.

ICU admission rates for those aged $\geqslant 65$ years increased only during the first 4 years. A substantial fall in admissions of those aged 65-79 years over the last 8 years resulted in a net reversal in the prevalence trend after 2004 ( $-1.7 \%$ per annum; $P=0.04$; Box $3)$. A similar decline $(-1.6 \%$ per annum) was observed in the mechanical ventilation subgroup (Appendix 1; online at www.mja.com.au).

Despite a $3.1 \%$ per annum rise in ICU admissions for patients aged $\geqslant 80$ years (from 10.5 to 14.0 admissions per 1000; Box 3), the net result was a fall in admissions for patients aged $\geqslant 65$ years and in the proportion of ICU beds occupied by older patients, from $51.9 \%$ to $48.6 \%(P=$ 0.02; Box 4).

\section{Length of stay}

The median hospital LOS for ICU patients aged $\geqslant 65$ years was 9 days (IQR, 5-17 days), including 1.9 days (IQR, 1.0-3.8 days) spent in an ICU. By comparison, young adults (aged $<65$ years) spent 7 days (IQR, 3-14 days; $P=0.01$ ) in hospital and 1.7 days (IQR, 0.9-3.6 days; $P=0.15$ ) in an ICU.

Hospital LOS was shorter for patients who died in hospital (6 days; IQR, 2-15 days) compared with those who survived (10 days; IQR, 6-17 days; $P=0.01$ ). There were no significant trends in hospital or ICU LOS over time $(P=0.49)$.

\section{Discussion}

More than 10000 patients aged $\geqslant 65$ years receive intensive care treatment in a public hospital in Victoria each year. Most (84\%) survive after a short period of acute care (6-17 days), and most return home. We made several observations worthy of comment.

There were divergent age-related trends in ICU admission rates. In line with previous reports, ${ }^{2,3}$ the prevalence of ICU admission for very old patients has continued to rise. However, this was offset by a decline in the admission rate for those aged 65-79 years after 2004, resulting in a net decline in ICU demand by older patients (Box 3).

There was a substantial improvement in the inhospital survival rate of older ICU patients (Box 2) without any increase in LOS or demand for RAC. We saw the same trends in high-acuity subgroups, and these improvements did not come at the expense of deaths in other hospital wards. We have previously reported improved survival for older patients not admitted to an ICU. ${ }^{21}$
3 Prevalence of intensive care unit admissions (per 1000 age-matched population) for patients aged $\geqslant 65$ years for the financial years 1999-2000 to 2010-2011
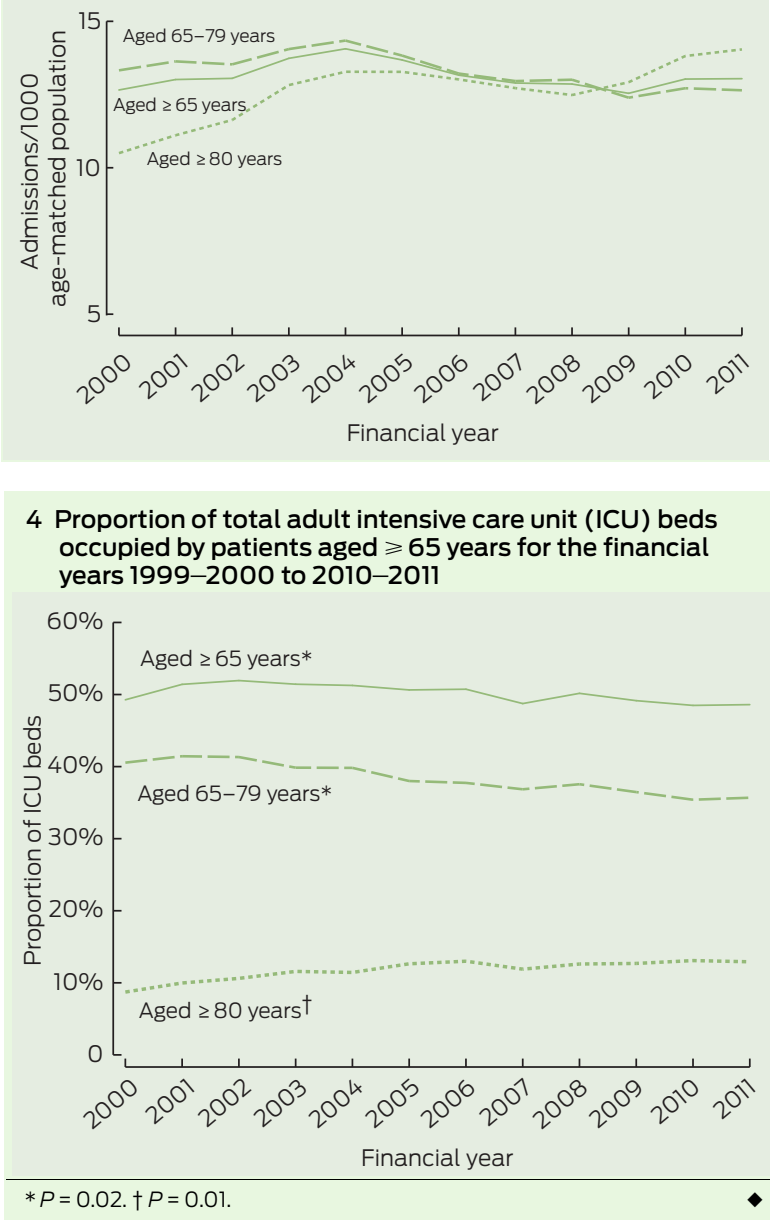

There are several plausible explanations for improved survival and the unexpected reversal in admission trends. It may simply reflect a global improvement in preventive health care and in treatment, together with a phase shift in disease presentation to an older age group ( $\geqslant 80$ years). Several recent advances in health care may have contributed to this, such as screening, preventive health care strategies, ambulatory care programs, minimally invasive surgery, interventional cardiology and targeted pharmacotherapy. These may have improved patients' access to, and the safety of, definitive treatment.

Survival gains did not appear to be secondary to restricting access to an ICU on the basis of age or acuity, or the result of protracted resuscitation in the ICU. Growth in the number of ICU beds (as a measure of resources) exceeded the growth of the population. Changes in demography and 
casemix were evident (Box 1) and these were accounted for in the riskadjustment models. ${ }^{19-21}$ There was no evidence of a temporal decline in the acuity of patients' conditions or in comorbidity scores, nor was there a rise in the surrogate markers of morbidity (LOS and demand for RAC beds).

Over $80 \%$ of all hospital deaths were in those aged $\geqslant 65$ years and most $(78 \%)$ were not admitted to an ICU before death. This proportion is lower than that reported in the United Kingdom $^{23}$ and higher than that in the United States, ${ }^{24}$ presumably reflecting geographic variations in access, triage and models of health care.

Early referral and intervention before ICU admission, multidisciplinary management, and rapid response to patients whose condition is deteriorating $^{25}$ are fundamental components of intensive care service delivery, and may be partly responsible for the observed improvements. End-oflife planning and access to palliative care are crucial for those with severe illness or irreversible disease. ${ }^{26}$

There are several important limitations to our analysis. These include the observational design and the absence of detailed clinical data or private sector workload (where casemix and service models differ from those in the public sector). We did not have data on cost versus benefit, or long-term or functional outcomes. Further research is required to investigate these areas. Until more data are available we cannot unequivocally claim that access to, and the outcomes of, care for older age patients has improved.

Despite these caveats, the results appear compelling. Declining demand for intensive care admission together with improved hospital survival, without an increase in surrogate measures of morbidity, are consistent with an improvement in the overall care of the important and potentially vulnerable older population.

Competing interests: No relevant disclosures.

Received 30 Jan 2013, accepted 25 Oct 2013.

1 Australian Bureau of Statistics. Population estimates by age and sex, Victoria by statistical geography, ASGS 2011. Canberra: ABS, 2013. (ABS Cat. No 3235.0.) http://www.abs. gov.au/ AUSSTATS/abs@.nsf/DetailsPage/3235. 02012?OpenDocument (accessed Dec 2013).

2 Bagshaw SM, Webb SA, Delaney A, et al. Very old patients admitted to intensive care in Australia and New Zealand: a multi-centre cohort analysis. Crit Care 2009; 13: R45.

3 Ryan D, Conlon N, Phelan D, Marsh B. The very elderly in intensive care: admission characteristics and mortality. Crit Care Resusc 2008; 10: 106-110.

4 de Rooij SE, Govers AC, Korevaar JC, et al. Cognitive, functional, and quality-of-life outcomes of patients aged 80 and older who survived at least 1 year after planned or unplanned surgery or medical intensive care treatment. J Am Geriatr Soc 2008; 56: 816-822.

5 Frost DW, Fowler R. Oncoming tides in the Age(ing) of Aquarius. Crit Care 2009; 13: 145

6 Nagappan R, Parkin G. Geriatric critical care. Crit Care Clin 2003; 19: 253-270.

7 Dodds S. Gender, ageing, and injustice: social and political contexts of bioethics. J Med Ethics 2005; 31: 295-298.

8 Holt AW, Vedig AE. Do advance care directives improve acute care services for older people? Med J Aust 2006; 185: 406.

9 Engelhardt HT Jr, Rie MA. Intensive care units, scarce resources, and conflicting principles of justice. JAMA 1986; 255: 1159-1164.

10 Yayan J. Trends in intensive care in patients over 90 years of age. Clin Interv Aging 2012; 7: 339-347.

11 Kerridge IH, McPhee J, Garvey G, Towney P. Discrimination in medicine: the uncertain role of values. Intern Med J 2001; 31: 541-543.
12 Duke GJ, Barker A, Santamaria JD, et al. A brief review of recent trends In Victorian intensive care: 1999-2011. Crit Care Resusc 2014; 16: 24-28.

13 Duke GJ, Buist MD, Pilcher D, et al. Interventions to circumvent intensive care access block: a retrospective 2-year study across metropolitan Melbourne. Med J Aust 2009; 190: 375-378.

14 Department of Health, Victoria. Victorian admitted episodes dataset (VAED) manual. 22nd ed, July 2012. http://www.health. vic.gov.au/hdss/vaed/2012-13/manual/sectl_ 2012.pdf (accessed Dec 2013).

15 Department of Health, Victoria. Critical care services in Victoria's public hospitals. August 2010. http://www.health.vic.gov.au/criticalcare/ ccu.htm (accessed Jun 2013).

16 Roberts RF, Innes KC, Walker SM. Introducing ICD10-AM in Australian hospitals. Med J Aust 1998; 169: 32-35.

17 Charlson ME, Pompei P, Ales KL, MacKenzie CR. A new method of classifying prognostic comorbidity in longitudinal studies: development and validation. J Chronic Dis 1987; 40: 373-383.

18 Elixhauser A, Steiner C, Harris DR, Coffey RM. Comorbidity measures for use with administrative data. Med Care 1998; 36: 8-27.

19 Duke GJ, Barker A, Rasekaba T, et al. Development and validation of the critical care outcome prediction equation (COPE) version 4 Crit Care Resusc 2013; 15: 191-197.

20 Duke GJ, Graco M, Santamaria J, Shann F. Validation of the hospital outcome prediction equation (HOPE) model for monitoring clinical performance. Intern Med J 2009; 39: 283-289.

21 Duke G, Barker A, Santamaria J, Graco M. Recent trends in Victorian risk-adjusted in-hospital mortality: 1999-2009. Intern Med J 2012; 42: 1218-1223.

22 Hilbe JM. Negative binomial regression. 2nd ed. Cambridge, UK: Cambridge University Press, 2011.

23 Wunsch $\mathrm{H}$, Linde-Zwirble WT, Harrison DA, et al. Use of intensive care services during terminal hospitalizations in England and the United States. Am J Respir Crit Care Med 2009; 180 : 875-880.

24 Angus DC, Barnato AE, Linde-Zwirble WT, et al. Use of intensive care at the end of life in the United States: an epidemiologic study. Crit Care Med 2004; 32: 638-643.

25 Jones DA, DeVita M, Bellomo R. Rapid-response teams. N Engl J Med 2011; 365: 139-146.

26 Silvester W, Fullam RS, Parslow RA, et al. Quality of advance care planning policy and practice in residential aged care facilities in Australia. BMJ Support Palliat Care 2012; 3: 349-357. 